P0101

\title{
EVALUATION WAY OF EFFECT COATINGS APPLYING GONIO-PHOTOMETRIC SPECTRAL IMAGING \\ Masayuki Osumi
}

DOI 10.25039/x46.2019.PO101

from

CIE x046:2019

Proceedings

of the

29th CIE SESSION

Washington D.C., USA, June 14 - 22, 2019

(DOI 10.25039/×46.2019)

The paper has been presented at the 29th CIE Session, Washington D.C., USA, June 14-22, 2019. It has not been peer-reviewed by CIE.

(C) CIE 2019

All rights reserved. Unless otherwise specified, no part of this publication may be reproduced or utilized in any form or by any means, electronic or mechanical, including photocopying and microfilm, without permission in writing from CIE Central Bureau at the address below. Any mention of organizations or products does not imply endorsement by the CIE.

This paper is made available open access for individual use. However, in all other cases all rights are reserved unless explicit permission is sought from and given by the CIE.

CIE Central Bureau

Babenbergerstrasse 9

A-1010 Vienna

Austria

Tel.: +4317143187

e-mail: ciecb@cie.co.at

www.cie.co.at 


\title{
EVALUATION WAY OF EFFECT COATINGS APPLYING GONIO- PHOTOMETRIC SPECTRAL IMAGING
}

\author{
Osumi, M. ${ }^{1}$ \\ 1 Office Color Science Co., Ltd., Yokohama, JAPAN \\ masayuki-osumi@nifty.com
}

DOI 10.25039/x46.2019.PO101

\begin{abstract}
To evaluate effect coatings, main idea is the use of combined colour and imaging information by gonio-photometric. In this study, a gonio-photometric spectral imaging system was applied to measuring colour and texture of effect coatings. And to get highly accurate spectrum, each wavelength images was compensated to small pixel shift by black and white lattice pattern measuring. Before compensation, measuring image was included a lot of the image registration error around peripheral part of black lattice line and reflectance profile was not horizontal and irregularity. On the other hands, in the image applying pixel shift compensation was disappeared the false colour and registration error was decreased. The sample panels were prepared with interference micas and absorption pigment by spray application. After measuring, the CIELAB colour value, the spatial distribution in CIELAB colour space, three sparkle index that is sparkle intensity, sparkle area and Laplacian filter were calculated. Analysis results in this study showed each value was related with characteristics of effect material.
\end{abstract}

Keywords: Spectral Imaging, Effect Coating, Evaluation, Gonio-photometric, Sparkle Index

\section{Introduction}

Metallic and pearlescent colours such as recent automotive exterior coatings include many types of effect pigments and apply multilayer coatings. Effect coatings have colour, feel, and texture such as various sparkle and graininess images related with visual perceptions depending on incident and observation angle.

\section{Method}

The main idea of evaluation is the use of combined colour and imaging information by goniophotometric. In this study, a gonio-photometric spectral imaging system was applied to measuring colour and texture of effect coatings. It was composed of white LED illuminates, a liquid crystalline tuneable filter (LCTF), and CCD imaging device with Peltier cooler and antiblooming function. To get highly accurate spectrum, each wavelength images was compensated to small pixel shift by black and white lattice pattern measuring. 5 effect coating samples were used. They were prepared with aluminium flake and interference micas by spray application. After measuring, the CIELAB colour value, the spatial distribution in CIELAB colour space, sparkle index was calculated.

\subsection{Measurement System}

Gonio-photometric spectral imaging system was composed of white LED illuminations, LCTF, and CCD imaging device with Peltier cooling unit. Illuminations angles were 20, 45 and 70 degrees from normal direction, and detective direction was normal against sample, and the CCD device captures the images via the LCTF from 420 to $700 \mathrm{~nm}$ with each $10 \mathrm{~nm}$ and $380 \mathrm{dpi}$ resolution of 772 by 580 pixels. Especially, it was considered the best ways of objective lens angle, CCD device resolution and illumination direction and distance to get highly sharpness for all measured area of effect coatings, and various optics dimensions were included in this image. 


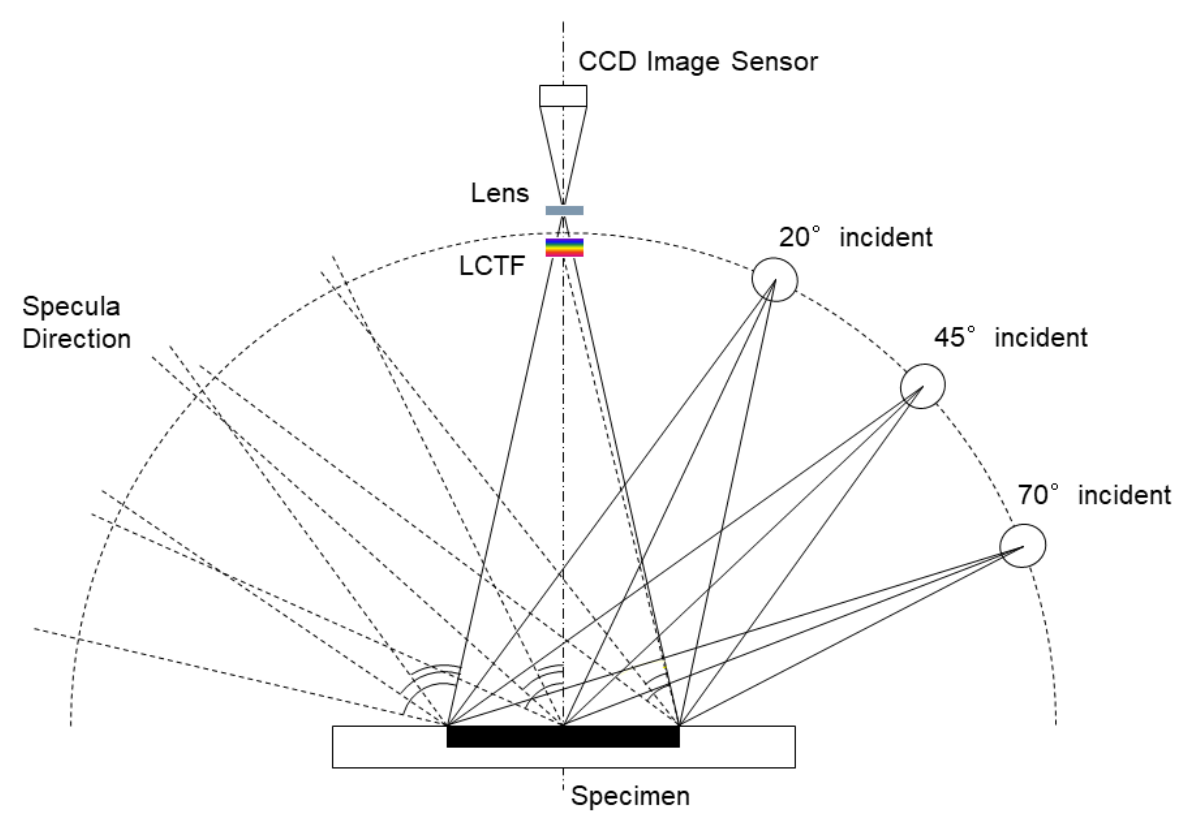

Figure 1 - Optical Dimension of Gonio-photometric Spectral Imaging

\subsection{Sample Preparation}

The effect coating test panels were prepared composed of absorption pigment and interference micas. Each panel was coated by spray application on black and white substrates. The thickness of base coat layer was 20 micrometres, and applied transparent clear top coat layer thickness was 35 micrometres. Each Panels formulation are shown in Table 1.

Table 1 - Sample Formulation

\begin{tabular}{|l|l|}
\hline & \multicolumn{1}{|c|}{ Formulation } \\
\hline No.1 & Xirallic Crystal Silver=1.0\%, FW200 $=0.3 \%$ \\
\hline No.2 & Xirallic Crystal Silver $=2.5 \%, \mathrm{FW} 200=0.3 \%$ \\
\hline No.3 & F.Turquoise $=1.50 \%, \mathrm{FW} 200$ Black $=0.05 \%$, Yellow $=1.00 \%$, Rose $=1.00 \%$ \\
\hline No.4 & F.Indigo $=1.00 \%$, F.Lilac $=1.00 \%$, FW200 Black $=0.05 \%$, Blue $=1.00 \%$, Rose $=0.50 \%$ \\
\hline No.5 & $\begin{array}{l}\text { F.Indigo }=1.00 \%, \text { Xirallic Crystal Silver }=1.50 \%, \text { FW200 Black } 0.05 \%, \text { Blue }=1.00 \%, \\
\text { Green }=0.30 \%\end{array}$ \\
\hline
\end{tabular}

\subsection{Pixel Shift Compensation}

In the case of Spectral Imaging, shift amount is within one or two pixel and not large. On the other hand, registration error which caused by pixel shift is one of large influence problem for applying metallic and pearlescent colour. Especially, effect pigment has sharp and high intensity sparkle, measured image is included high contrast and small dot size image. Almost spectral imaging system has pixel shift behaviour with optics imperfection such as colour abrasion, inaccuracy of optical axis etc. To get highly accurate gonio-photometric spectrum reflectance and imaging information, each wavelength sample images was compensated by measured lattice pattern to get small shift amount of $x$ and $y$ direction. Before sample measuring, the lattice pattern composed of white and black line was applied to compensation for registration error which was caused by LCTF optical aberration of each wavelength images. The compensation calculation way is following steps.

- Prepare lattice pattern combined with white substrate and black line.

Line width is around 2 or 3 pixels.

- Measure lattice pattern by spectral imaging.

- Make invert image. 
- After applying moving average processing, peak position sensing by deviation calculation for each wavelength image.

- Calculation shift amount of $X$ and $Y$ direction on peak position for all measurement.

- Compensation calculation applying interpolation between peak position.

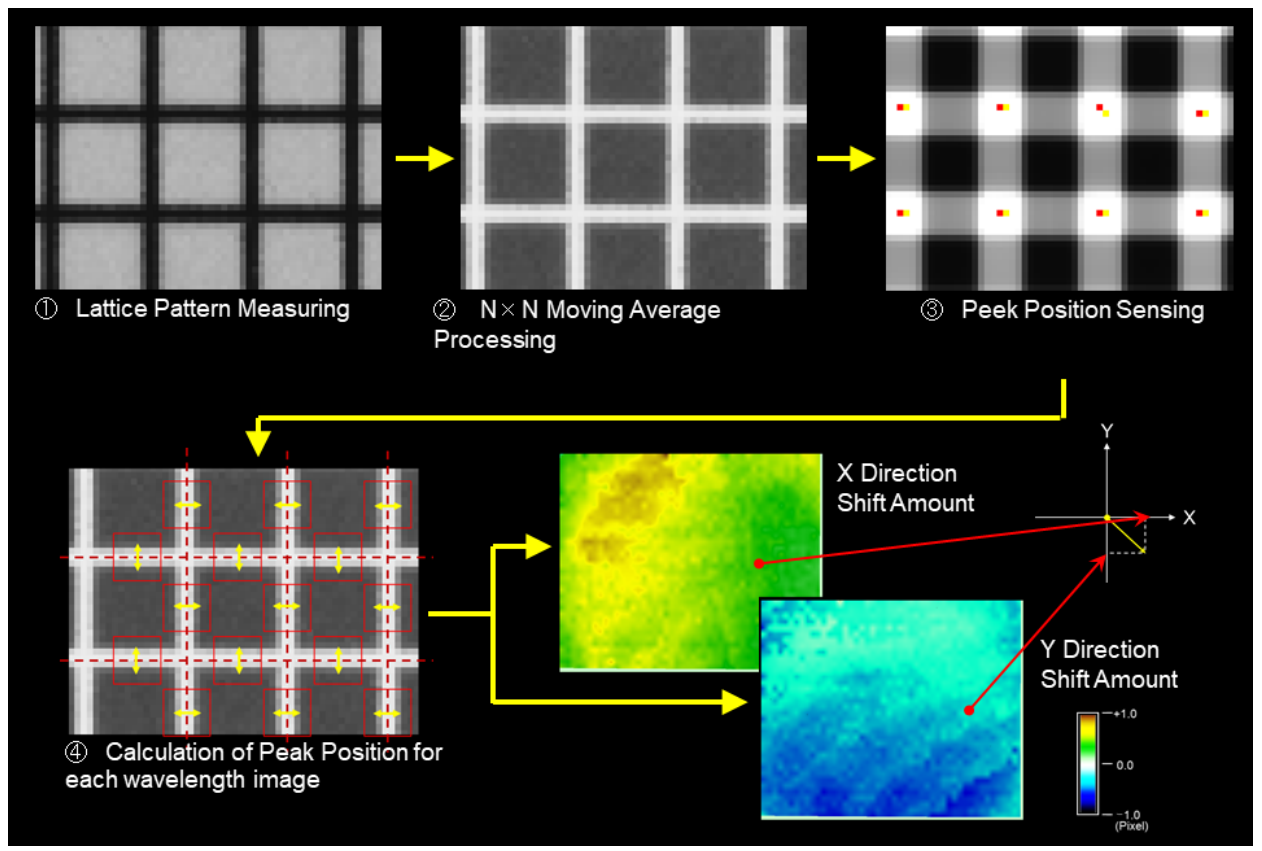

Figure 2 - Schematic Diagram of Pixel Shit Compensation

\subsection{Image Processing}

In this study, following three indexes are calculated for after measuring spectral imaging.

'Sparkle Intensity (Si)' as follows:

$$
\text { Sparkle Intencity }[S i]=\frac{1}{T} \sum_{\substack{0 \leq i \leq \leq \leq \leq n \\ 0 \leq j \leq n}}[P(i, j)-B l] \quad P(i, j)>B l
$$

where

$P(i, j)$ : Each pixel Image Value, $L^{*}, C^{*}, L^{*} \times C^{*}$

$B l$ : Baseline,

$T$ : Number of pixel $(m \times n)$.

'Sparkle Area (Sa)' as follows:

$$
\text { Sparkle Area }[S a]=\alpha\left\{\frac{1}{T} \sum_{\substack{0 \leq i \leq \mathrm{m} \\ 0 \leq \mathrm{j} \leq \mathrm{n}}}[1]\right\}^{2} \quad P(i, j)>B l
$$

where

$\alpha$ : Normalization factor,

$P(i, j)$ : Each pixel Image Value, $L^{*}, C^{*}, L^{*} \times C^{*}$

$B l$ : Baseline,

$T$ : Number of pixel $(m \times n)$.

'Laplacian filter $(L f)$ ' as follows: 
Laplacian Filter $[L f]=\alpha \frac{1}{T} \sum_{\substack{1<i<\mathrm{i} \\ 1<\mathrm{j}<\mathrm{n}}}|\boldsymbol{M}(i, j) \times \boldsymbol{L}|$

where

$\alpha$ : Normalization factor,

$M(i, j): 3 \times 3$ Matrix pixel Image Value, $L^{*}, C^{*}, L^{*} \times C^{*}$

$B l$ : Baseline,

$T$ : Number of pixel $(m \times n)$,

L: Laplacian filter $3 \times 3$ Matrix

$\boldsymbol{L}=\left[\begin{array}{ccc}0 & -1 & 0 \\ -1 & 4 & -1 \\ 0 & -1 & 0\end{array}\right]$

\section{Result}

\subsection{Pixel Shift Compensation}

The lattice pattern image applying pixel shift compensation was shown in Figure 3. Before compensation, measuring image was included a lot of the false colour around peripheral part of black lattice line and reflectance profile was not horizontal and irregularity. On the other hands, in the image applying pixel shift compensation was disappeared the false colour disappeared and decreased registration error was decreased. Finally, this system could get highly accurate gonio-photometric spectral reflectance and colour values in a wide a-specular angle range from 3.5 to 80.8 degrees. Spectral imaging was checked positioning differences in the centre and peripheral part of the images for each wave length were checked for the spectral imaging, and confirmed high accuracy all over the images with no pixel shift.

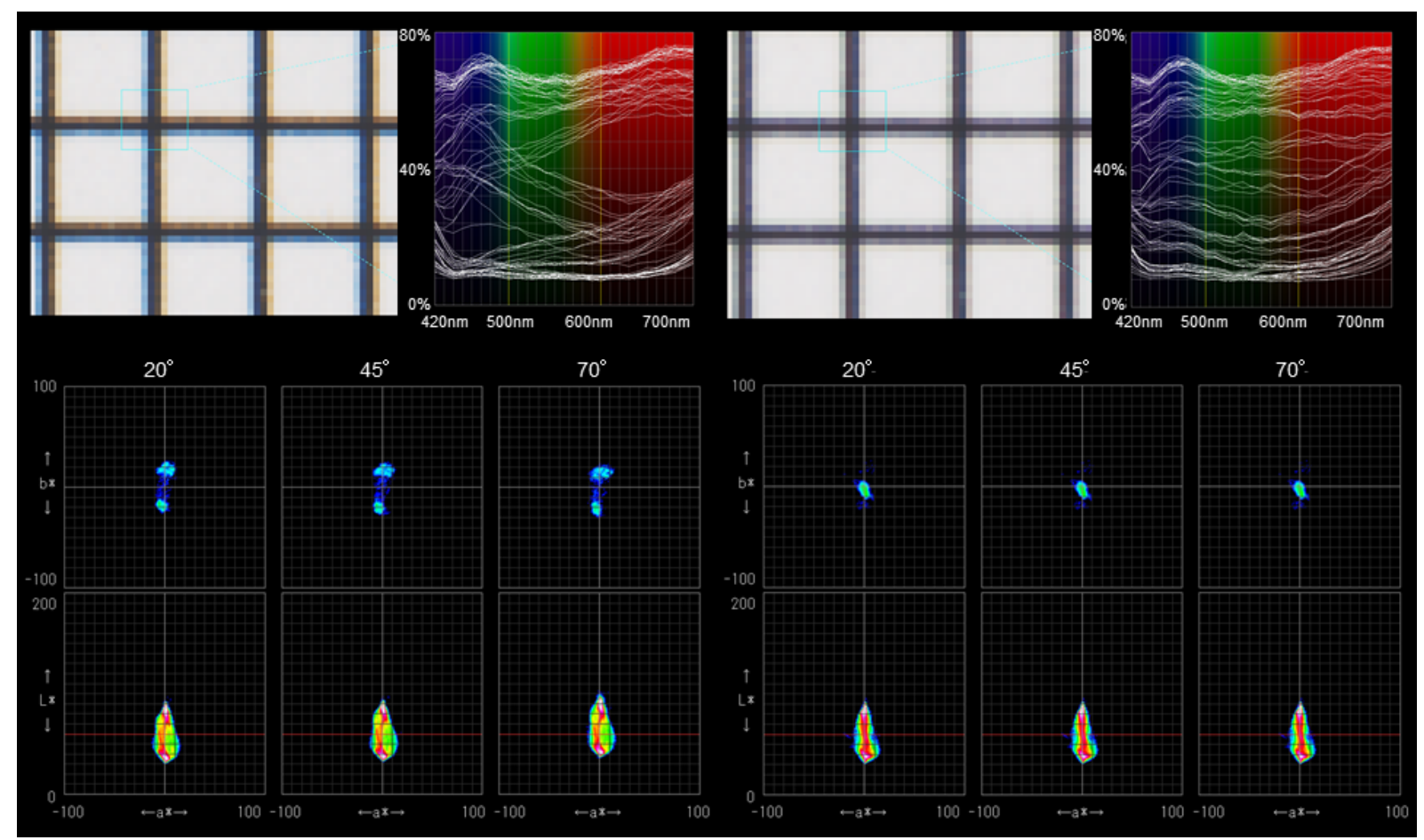

Figure 3 - Result of Pixel Shift Compensation Spatial Distribution in CIELAB Colour Space of Lattice Image

\subsection{Gamut Distribution in CIELAB Colour Space}

As an example, the measuring result of Xirallic Crystal Silver with FW200 cabon black pigment is shown in Figure 2. The distribution in CIELAB colour space calculated from measured spectral imaging of 20 degrees illuminant is shown in this figure. Right side 
shows the frequency of occurrence projected to $L^{*}-a^{*}$ plane, and left side shows the frequency of occurrence to projected $a^{*}-b^{*}$ plane at $L^{*}=15$ with optimal colour area. The important point to note is measured colour occurrence area has quite wide distribution with all over the optimal colour area. This result suggests that rescent effect materials need spectral imaging measurement to get high accurate $L^{*} a^{*} b^{*}$ value of spakle texture.

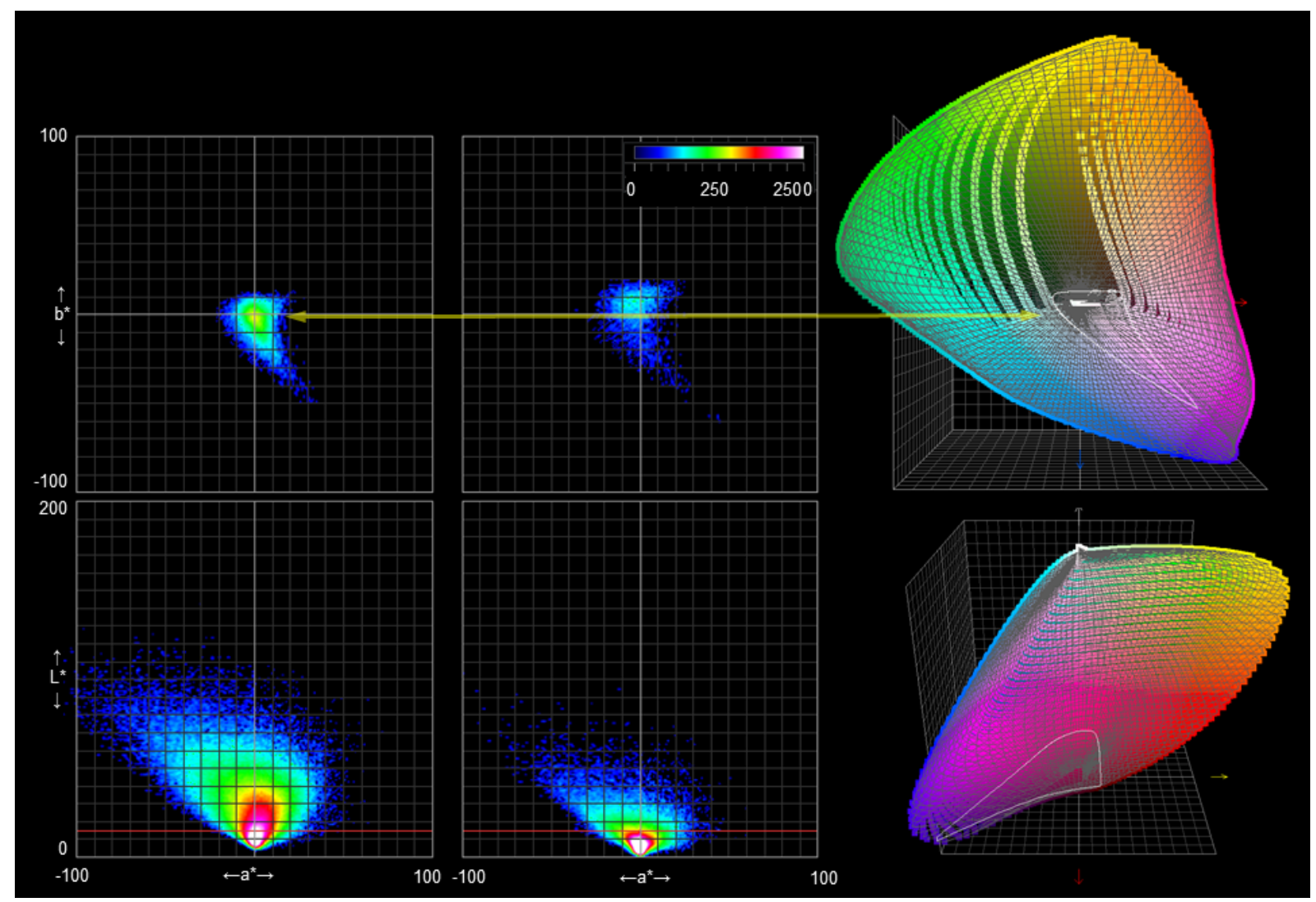

Figure 4 - Image Distribution with Optimal Colour Area in CIELAB Colour Space Xirallic Crystal Silver/FW200 $=1.0 / 0.3 \%$

\subsection{Sparkle Measurement Result}

The measurement result of gonio-photometric spectral imaging with a-specula angle is shown in Figure $5 . \mathrm{X}$ axis of measurement image is related with specula direction, and system can measure from 3.5 to $80.8 \mathrm{deg}$. a-specula angle by 20,45 , and 70 deg. incident illuminations. Each pixel has spectral information, and calculated $L^{*}, C^{*}, L^{*}$ multiply $C^{*}$ value. Xirallic Crystal Silver (Merck $\mathrm{Gmbh}$ ) has $\mathrm{Al}_{2} \mathrm{O}_{3}$ synthetic mica and appeared strong sparkle. Near by 3.5 deg. $C^{*}$ distribution is very wide and recognized a lot of high chromatic sparkle. The calculation results of Xirallic Crystal Silver three sparkle index, sparkle intensity, sparkle area, and Laplacian filter are shown in Figure 6 and 7 . Figure 6 is nearby 3.5 deg. result, and Figure 7 is nearby $35.0 \mathrm{deg}$. by $20 \mathrm{deg}$. incident illumination. Figure 8,9 and 10 are shown measurement and calculated result of colour panel which mixed with interference mica and absorption pigment. 


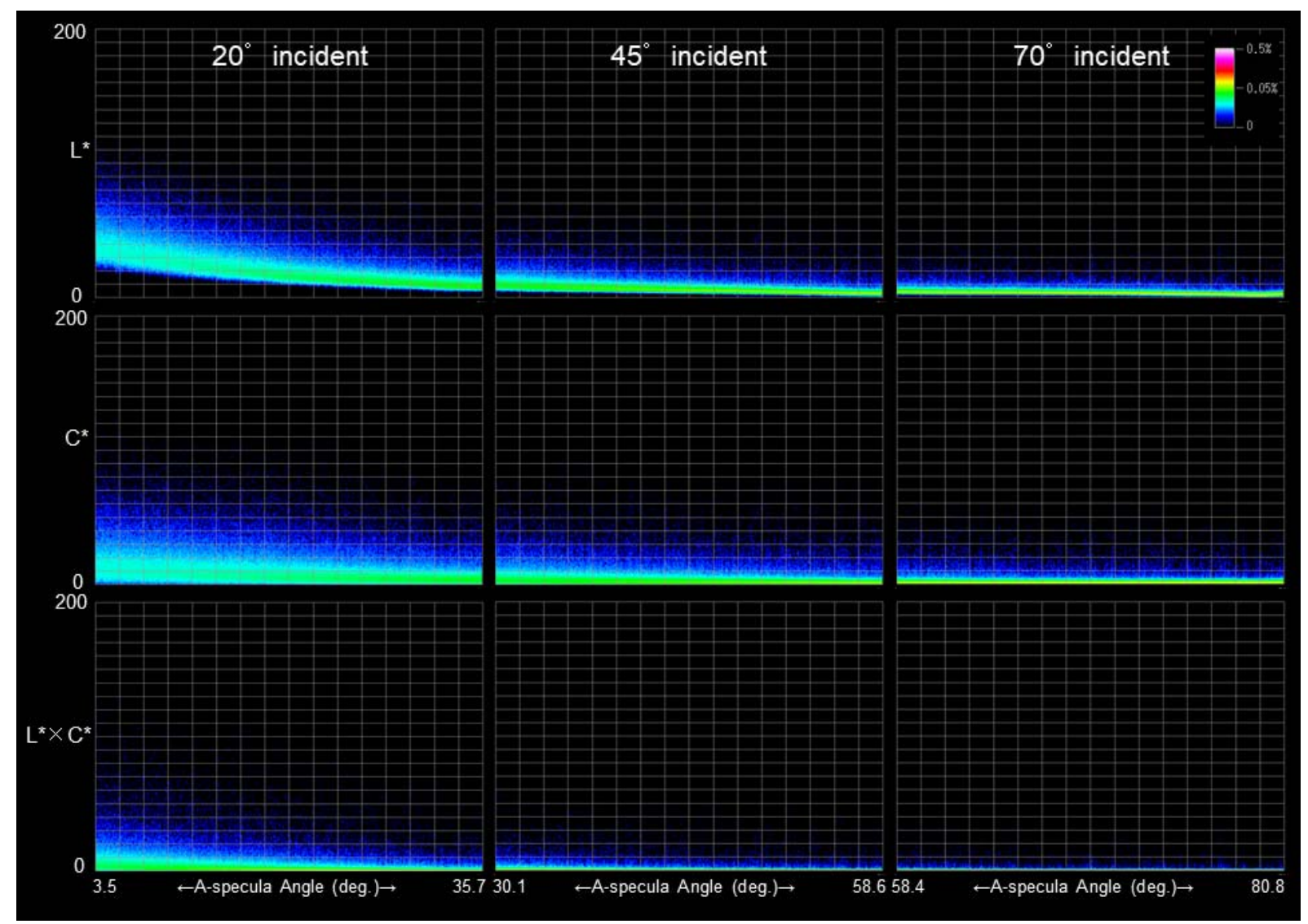

Figure 5 - Measurement Result of Gonio-photometric Spectral Imaging $L^{*}, C^{*}, L^{*} \times C^{*}$ Distribution with A-specula Angle, Xirallic Crystal Silver/FW200 $=1.0 / 0.3 \%$

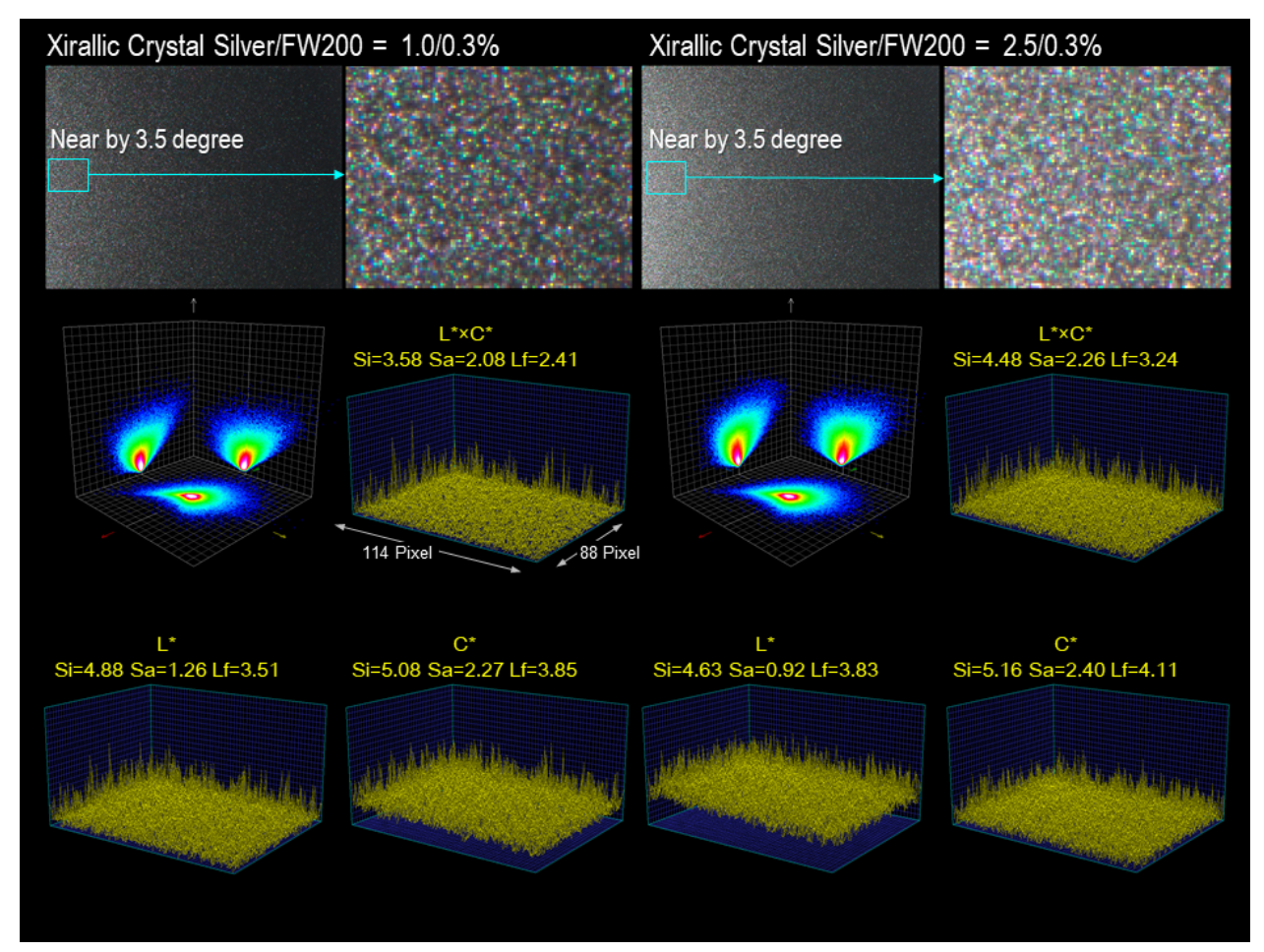

Figure 6 - Measurement Result of Gonio-photometric Spectral Imaging Xirallic Crystal Silver/FW200 $=1.0 / 0.3 \%$ and Xirallic Crystal Silver/FW200 $=\mathbf{2 . 5 / 0 . 3 \%}$ Incident 20 deg., A-specula nearby $3.5 \mathrm{deg}$. 


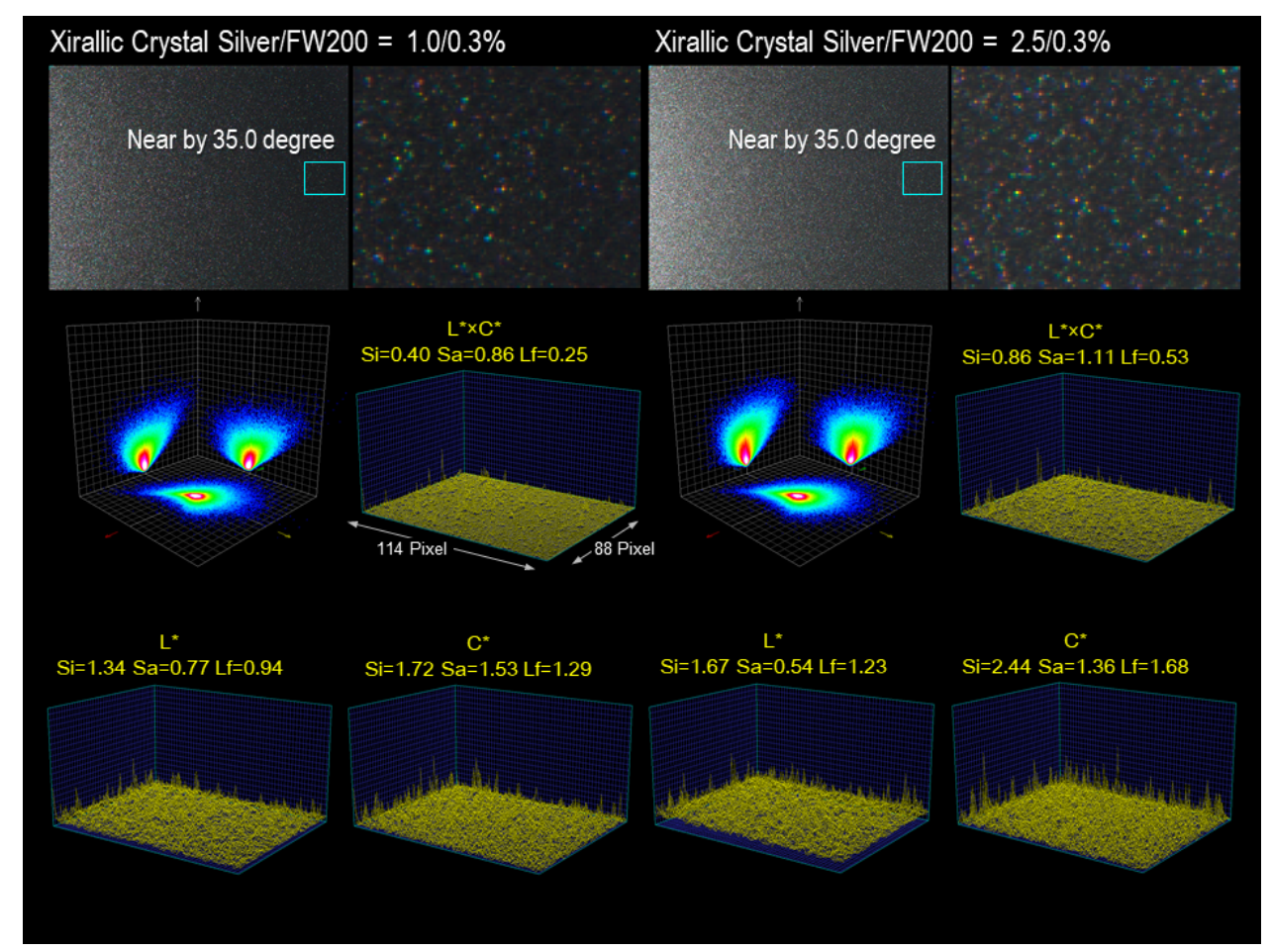

Figure 7 - Measurement Result of Gonio-photometric Spectral Imaging Xirallic Crystal Silver/FW200 $=1.0 / 0.3 \%$ and Xirallic Crystal Silver/FW200 $=\mathbf{2 . 5} / 0.3 \%$ Incident 20 deg., A-specula nearby 35.0 deg.

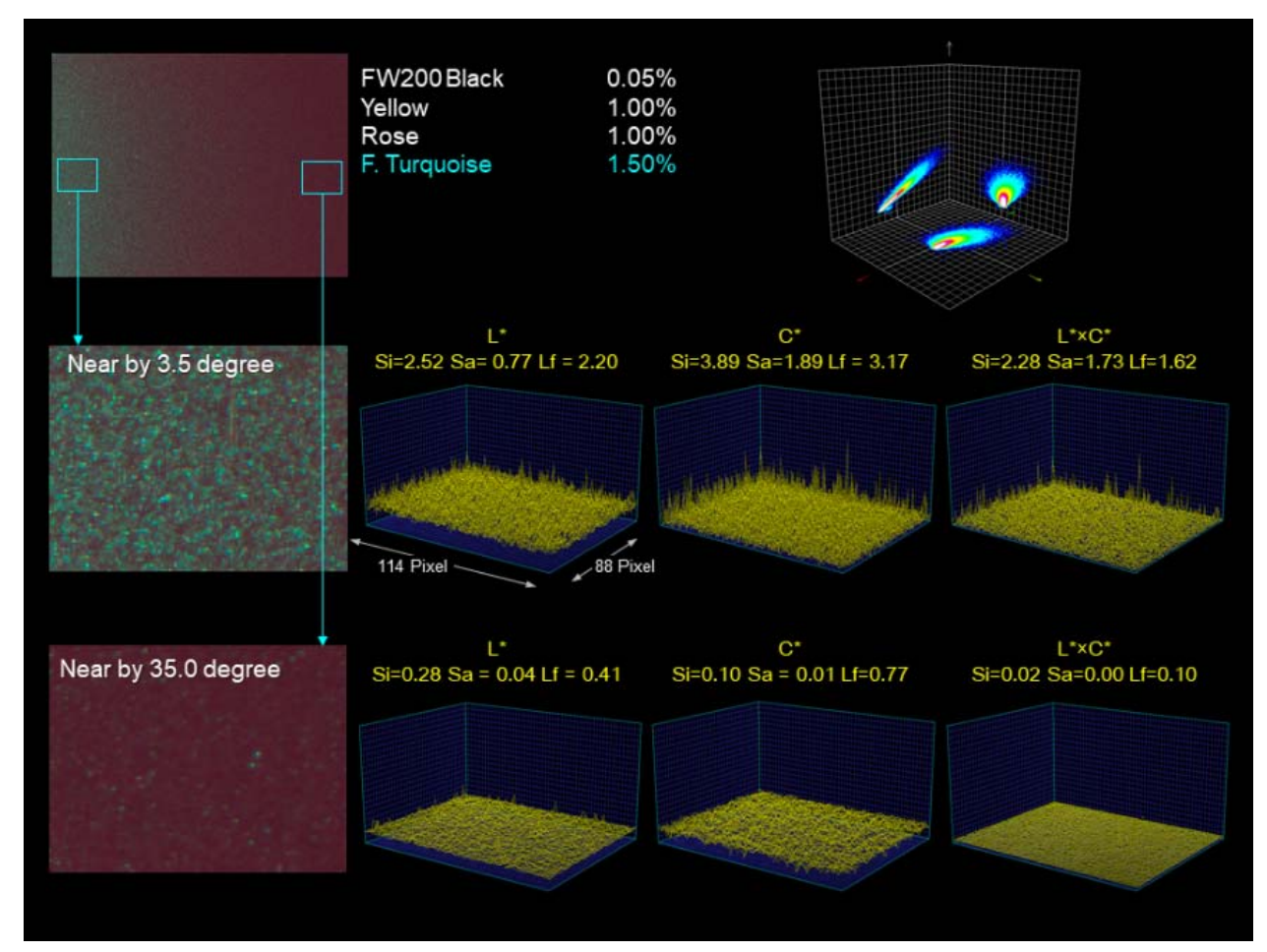

Figure 8 - Measurement Result of Gonio-photometric Spectral Imaging Sample Number 3, Incident 20 deg. 




Figure 9 - Measurement Result of Gonio-photometric Spectral Imaging Sample Number 4, Incident 20 deg.

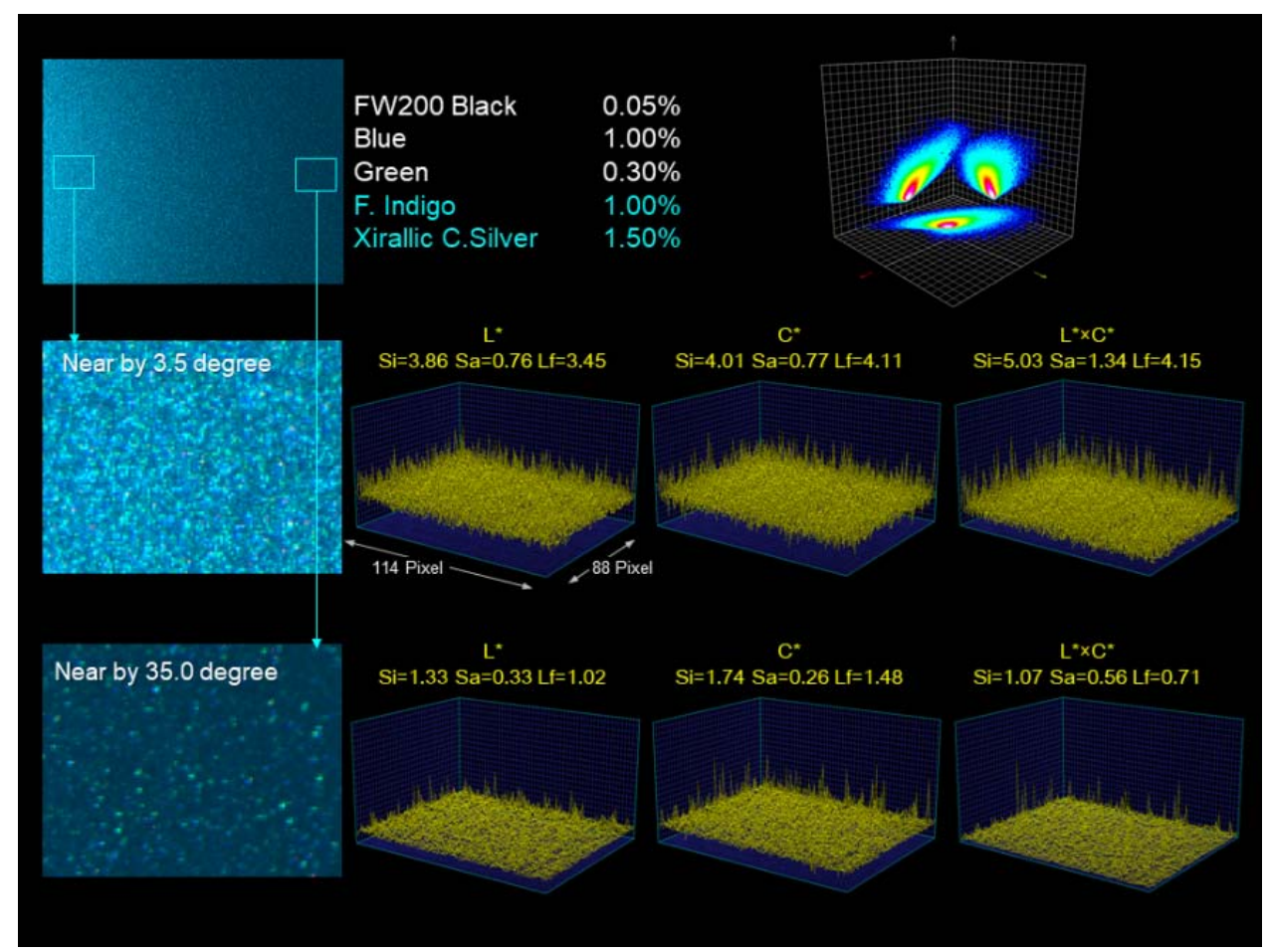

Figure 10 - Measurement Result of Gonio-photometric Spectral Imaging Sample Number 5, Incident 20 deg.

\section{Conclusion}

Developed Gonio spectral imaging system was composed by LCTF, CCD image sensor, and LED illumination. It was confirmed interference pigment had a very wide colour area. Developed system can get various and high accurate gonio-photometric spectral imaging information by short measuring time with no movement and simple structure. Moreover, this system has 
possibility to get high dimensional information such as distribution in CIELAB colour space and colourful sparkle index. Especially, automotive exterior coatings apply many kinds of interference effect material and they include high chromatic sparkle with sharp and high contrast image depending on optical dimension. Gonio-photometric spectral imaging with no registration error and simple measuring way is very important.

\section{References}

Tsai Du-Yih, Lee Yongbum, Matsuyama, Information-Entropy Measure for Evaluation of Image Quality, Journal of Digital Imaging, Springer New York، 2007

Hensley, D. Wyble, Spectral Imaging Using a Liquid Crystal Tuneable Filter, Munsell Colour Science Laboratory, Technical Report November 2012 